\title{
SARS-CoV-2 genomic characterization and clinical manifestation of the COVID-19 outbreak in Uruguay
}

Victoria Elizondo, Gordon W. Harkins, Batsirai Mabvakure , Sabine Smidt , Paul Zappile, Christian Marier, Matthew T. Maurano, Victoria Perez, Natalia Mazza, Carolina Beloso, Silvana Ifran , Mariana Fernandez, Andrea Santini , Veronica Perez, Veronica Estevez, Matilde Nin , Gonzalo Manrique, Leticia Perez , Fabiana Ross, Susana Boschi , Maria Noel Zubillaga, Raquel Balleste, Simon Dellicour, Adriana Heguy \& Ralf Duerr

To cite this article: Victoria Elizondo, Gordon W. Harkins, Batsirai Mabvakure , Sabine Smidt , Paul Zappile, Christian Marier, Matthew T. Maurano, Victoria Perez, Natalia Mazza, Carolina Beloso, Silvana Ifran , Mariana Fernandez , Andrea Santini , Veronica Perez, Veronica Estevez, Matilde Nin , Gonzalo Manrique , Leticia Perez , Fabiana Ross , Susana Boschi , Maria Noel Zubillaga , Raquel Balleste , Simon Dellicour , Adriana Heguy \& Ralf Duerr (2021) SARS-CoV-2 genomic characterization and clinical manifestation of the COVID-19 outbreak in Uruguay, Emerging Microbes \& Infections, 10:1, 51-65, DOI: 10.1080/22221751.2020.1863747

To link to this article: https://doi.org/10.1080/22221751.2020.1863747
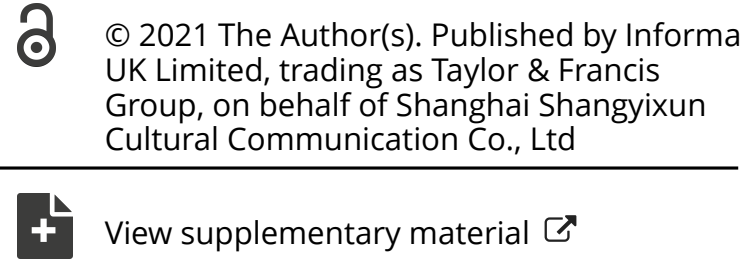

View supplementary material $₫$

$$
\text { 册 Published online: 15 Jan } 2021 .
$$

\section{[6] Submit your article to this journal $\square$}

Џll Article views: 937 
(

Full Terms \& Conditions of access and use can be found at https://www.tandfonline.com/action/journallnformation?journalCode=temi20 


\title{
SARS-CoV-2 genomic characterization and clinical manifestation of the COVID-19 outbreak in Uruguay
}

\author{
Victoria Elizondo ${ }^{a *}$, Gordon W. Harkins $\mathbb{C}^{\mathrm{b} *}$, Batsirai Mabvakure ${ }^{\mathrm{c} *}$, Sabine Smidt ${ }^{\mathrm{b}}$, Paul Zappile ${ }^{\mathrm{d}}$, \\ Christian Marier $^{\mathrm{d}}$, Matthew T. Maurano ${ }^{\mathrm{e}, \mathrm{f}}$, Victoria Perez ${ }^{\mathrm{a}, \mathrm{g}}$, Natalia Mazza $\mathbb{1}^{\mathrm{a}}$, Carolina Beloso ${ }^{\mathrm{a}, \mathrm{h}}$, \\ Silvana Ifran ${ }^{\mathrm{a}}$, Mariana Fernandez ${ }^{\mathrm{a}}$, Andrea Santini ${ }^{\mathrm{a}}$, Veronica Perez ${ }^{\mathrm{a}}$, Veronica Estevez ${ }^{\mathrm{a}}$, Matilde Nin ${ }^{\mathrm{a}}$, \\ Gonzalo Manrique ${ }^{a}$, Leticia Perez ${ }^{a}$, Fabiana Ross ${ }^{a}$, Susana Boschi ${ }^{a}$, Maria Noel Zubillaga ${ }^{a}$, Raquel Balleste ${ }^{a}$, \\ Simon Dellicour (1) ${ }^{i, j}$, Adriana Heguy (10) ${ }^{\mathrm{d}, \mathrm{e}}$ and Ralf Duerr (1) ${ }^{\mathrm{e}}$
}

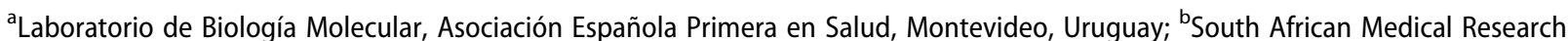
Council Capacity Development Unit, South African National Bioinformatics Institute, University of the Western Cape, Bellville, South Africa; 'Department of Medicine, Johns Hopkins School of Medicine, Baltimore, MD, USA; ${ }^{d}$ Genome Technology Center, Office for Science and Research, NYU Langone Health, New York, NY, USA; 'Department of Pathology, NYU Grossman School of Medicine, New York, NY, USA; f Institute for Systems Genetics, NYU Grossman School of Medicine, New York, NY, USA; ${ }^{9}$ Departamento de Desarrollo Biotecnológico, Instituto de Higiene, Facultad de Medicina, Udelar, Montevideo, Uruguay; ${ }^{\text {h}}$ Departamento de Biodiversidad y Genética. Instituto de Investigaciones Biológicas Clemente Estable, Montevideo, Uruguay; 'Spatial Epidemiology Lab. (SpELL), Université Libre de Bruxelles, Bruxelles, Belgium; 'Department of Microbiology, Immunology and Transplantation, Rega Institute, Leuven, Belgium
\end{abstract}

\begin{abstract}
COVID-19 is a respiratory illness caused by severe acute respiratory syndrome coronavirus 2 (SARS-CoV-2) and declared by the World Health Organization a global public health emergency. Among the severe outbreaks across South America, Uruguay has become known for curtailing SARS-CoV-2 exceptionally well. To understand the SARS-CoV-2 introductions, local transmissions, and associations with genomic and clinical parameters in Uruguay, we sequenced the viral genomes of 44 outpatients and inpatients in a private healthcare system in its capital, Montevideo, from March to May 2020. We performed a phylogeographic analysis using sequences from our cohort and other studies that indicate a minimum of 23 independent introductions into Uruguay, resulting in five major transmission clusters. Our data suggest that most introductions resulting in chains of transmission originate from other South American countries, with the earliest seeding of the virus in late February 2020, weeks before the borders were closed to all non-citizens and a partial lockdown implemented. Genetic analyses suggest a dominance of $S$ and $G$ clades $(G, G H, G R)$ that make up $>90 \%$ of the viral strains in our study. In our cohort, lethal outcome of SARS-CoV-2 infection significantly correlated with arterial hypertension, kidney failure, and ICU admission (FDR $<0.01$ ), but not with any mutation in a structural or nonstructural protein, such as the spike D614G mutation. Our study contributes genetic, phylodynamic, and clinical correlation data about the exceptionally well-curbed SARS-CoV-2 outbreak in Uruguay, which furthers the understanding of disease patterns and regional aspects of the pandemic in Latin America.
\end{abstract}

ARTICLE HISTORY Received 8 October 2020; Revised 23 November 2020; Accepted 9 December 2020

KEYWORDS SARS-CoV-2; COVID-19 outbreak; Uruguay; South America; full genome amplicon sequencing; spike D614G genetic mutation; phylogeographic BEAST analysis; clinical correlations

\section{Introduction}

The novel coronavirus SARS-CoV-2, first discovered in Wuhan, China, in December 2019, rapidly extended throughout the globe, and among the $>35$ million confirmed positive people from $>210$ affected countries and territories, $>1$ million have died from the rapidly-spreading SARS-CoV-2 virus as of October 5th, 2020 [1].

Even though South America was mostly spared in the early months of the pandemic and was the last continent where it spread, it was severely hit with the arrival of the fall season to the Southern hemisphere. The virus is currently ravaging Latin America, with Brazil, Colombia, Argentina, Peru, and Mexico among the ten countries with the highest numbers of cases worldwide. In contrast, Uruguay, a small country located south of Brazil, has succeeded in maintaining a very low number of total cases $(2,145)$ through the closing of its borders, a partial lockdown, and an early Test, Trace and Isolate (TETRIS) strategy [2]. Uruguay has a population of $\sim 3.3$ million inhabitants, of which more than a third ( $\sim 1.3$ million) live in the capital city of Montevideo, according to the last census in 2011 [3]. Montevideo is Uruguay's most interconnected city due to the presence of its international airport and harbour. The first positive case

CONTACT Victoria Elizondo $\otimes$ totiep@gmail.com; Adriana Heguy $\otimes$ Adriana.Heguy@nyulangone.org; Ralf Duerr $\bigotimes$ Ralf.Duerr@nyulangone.org *Shared first authors.

(4) Supplemental data for this article can be accessed https://doi.org/10.1080/22221751.2020.1863747.

(c) 2021 The Author(s). Published by Informa UK Limited, trading as Taylor \& Francis Group, on behalf of Shanghai Shangyixun Cultural Communication Co., Ltd This is an Open Access article distributed under the terms of the Creative Commons Attribution License (http://creativecommons.org/licenses/by/4.0/), which permits unrestricted use, distribution, and reproduction in any medium, provided the original work is properly cited. 
was officially registered on March $13^{\text {th }}$, and almost seven months later, 245,000 samples ( $>7 \%$ of the total population of Uruguay) had been tested. In March 2020, after the first four positive cases of SARS-CoV-2 were reported in Montevideo, the government issued a responsible voluntary quarantine in the country, involving the closure of schools, public entities, and businesses, urging the population to stay home [4]. On March $24^{\text {th }}$, land, maritime, and air borders were closed, allowing only Uruguayan citizens to enter the country [5]. As of October $5^{\text {th }}, 2020,2,145$ patients have tested positive, 1,831 recovered, 243 are active cases, and 48 patients died [6].

Viral genome sequencing (genomic surveillance) is a powerful approach to determine the origin of pathogen introductions into a certain location and trace and track the virus's subsequent spread and evolution. It has been utilized to complement other epidemiological parameters determined by testing, contact tracing and implementation of public health measures such as lockdowns [2,7-11].

Although preliminary phylogenetic analyses of Uruguayan SARS-CoV-2 sequences have previously been communicated on pre-print websites [2,7], there remains a critical lack of knowledge regarding SARS-CoV-2 mutation, dispersal, and transmission patterns, and whether statistical associations exist among viral genomic, demographic, and clinical features. For example, a detailed phylogeographic analysis has not been undertaken to investigate the global dispersal dynamics with respect to Uruguay.

In the present study, we describe and build on genomic surveillance of a private non-profit healthcare system in Uruguay's capital, Montevideo, where SARS-CoV-2 cases have been identified since March $17^{\text {th }}$. We have sequenced and characterized 44 positive cases spanning March to late May, complemented with 29 Uruguayan sequences downloaded from the GISAID database. The 73 sequences covered roughly $10 \%$ of the Uruguay cases at that moment (end of May)[12]. We build on the existing Nextstrain framework, a broadly used and universally recognized analytical platform for the analysis of global SARSCoV-2 viral genome sequence data that has accumulated since the start of the pandemic [13] to analyse newly sequenced SARS-CoV-2 genomes sampled in Uruguay, and combine it with Bayesian Evolutionary Analysis of Sampling Trees (BEAST).

An important aim of this study is to identify the different SARS-CoV-2 introduction events in Uruguay, located in a geographical region of the pandemic that has been understudied so far. Specifically, we aim at (i) identifying and investigating the importance of independent introduction events in establishing the COVID-19 epidemic in Uruguay, (ii) analysing the spatial distribution of the resulting clades in the capital city, Montevideo, (iii) looking for phylogenetic clusters within sampled institutions (hospitals, nursing homes), (iv) determining whether statistically significant correlations exist among mutations, demographic, and clinical parameters.

\section{Materials and methods}

\section{Bioethics, sample collection \& RNA extraction}

The molecular lab at the Asociación Española Primera en Salud (AEPS) is a fully accredited clinical lab, regulated by the Uruguayan Ministry of Health (Ministerio de Salud Pública, MSP). Sampling was done according to the regional IRB guidelines and the recommendations of the MSP. Our study was evaluated by the commission of bioethics and ethics in research of the AEPS, headed by Fernando García [14,15]. IRB approval was waived because the genetic analysis was restricted to the virus and not the host, and clinical correlation analyses were done on fully de-identified samples (UY ID and GISAID IDs given by the Uruguayan and New York research teams, respectively), and are not traceable to any medical record number. The participants provided informed oral consent, and the data were analysed anonymously. For participants $<18$ years of age, formal written or verbal consent was obtained from the parent/guardian at sampling, and data were kept anonymously for the entire study. The molecular clinical lab at AEPS is accredited for diagnostic RT-PCR tests for SARSCoV-2 (COVID-19) in Uruguay. Naso-oropharyngeal swabs were collected in viral transport media and RNA was extracted using the QIAsymphony ${ }^{\circledR}$ DSP Virus/Pathogen Mini or Midi kit (Qiagen), respectively. Confirmatory qualitative commercial RT-PCR kits were used for diagnosis and screening (depending on critical availability during the outbreak) (Table 1). Full details in Supplemental Methods.

\section{Library preparation, sequencing, and read processing}

To amplify the viral genomes in preparation for sequencing, we used the Swift Normalase Amplicon SARS-CoV-2 Panel (SNAP, Swift Biosciences, whole viral genome single tube NGS assay, cat\# SN5XCOV296). The libraries were run on an Illumina NovaSeq 6000300 cycle flow cell, as paired-end 150, using dual indices. Both positive and negative control samples were also run during library prep but not sequenced. The negative control sample was water, and the positive control sample consisted of SARSCoV-2 genomes (Twist Biosciences, cat\# 102024) serially diluted to 100 viral copies and mixed into $50 \mathrm{ng}$ of Universal Human Reference RNA (Agilent, cat\# 18091050). Sequencing reads were demultiplexed with Illumina bcl2fastq v.2.20 requiring a perfect 
Table 1. Overview of three different SARS CoV2 detection kits included in this study

\begin{tabular}{|c|c|c|c|c|c|c|}
\hline Real-time RT-PCR System & Country & Regulatory Status & $\begin{array}{l}\text { Target } \\
\text { Gene(s) }\end{array}$ & $\begin{array}{l}\text { Limit of Detection } \\
\text { (copies/reaction) }\end{array}$ & $\begin{array}{l}\text { Run Time } \\
\text { (hours) }\end{array}$ & PCR Machine \\
\hline $\begin{array}{l}\text { LightMix Modular SARS and } \\
\text { Wuhan CoV E/RdRp/N-gene } \\
\text { (TIB MOLBIOL) }\end{array}$ & Germany & RUO & $\begin{array}{l}\text { E, } \mathrm{N} \text { and } \\
\text { RdRp }\end{array}$ & $5-10$ & 1.2 & $\begin{array}{l}\text { LightCycler }^{\oplus} \text { z480 System, } \\
\text { ROCHE }\end{array}$ \\
\hline $\begin{array}{l}\text { GeneFinder COVID-19 Plus Real } \\
\text { Amp Kit (Healthcare) }\end{array}$ & Korea & $\begin{array}{l}\text { HealthCanada } \\
\text { BrazilANVISA } \\
\text { SingaporeHSA CE-IVD }\end{array}$ & $\begin{array}{l}\text { E, } N \text { and } \\
\text { RdRp }\end{array}$ & 10 & 2.2 & $\begin{array}{l}\text { CFX96 Touch Real-Time PCR } \\
\text { Detection System, BIO- } \\
\text { RAD }\end{array}$ \\
\hline $\begin{array}{l}\text { RealStar SARS- CoV-2RT-PCR kit } \\
1.0 \text { (Altona) }\end{array}$ & Germany & US FDAEUA CE-IVD & $E, S$ & NA & 2.25 & $\begin{array}{l}\text { CFX96 Touch Real-Time PCR } \\
\text { Detection System, BIO- } \\
\text { RAD }\end{array}$ \\
\hline
\end{tabular}

match to indexing barcode sequences, and aligned to the reference SARS-CoV-2 genome (NC_045512.2, wuhCor1). Only samples with $>4,000 \mathrm{x}$ mean viral coverage depth, $>23,000$ bp unmasked sequence, and $>0.3$ of reads mapping to the viral genome were further analysed. Variants were called using bcftools v.1.9. Details of the library generation and sequencing read processing are in the Supplemental Methods.

\section{Statistics}

D'Agostino \& Pearson normality tests were performed to assess whether data values followed a Gaussian distribution and whether parametric or nonparametric statistical tests were indicated (GraphPad Prism v.8). As a result, correlation analyses were done using nonparametric Spearman rank tests. Correlation coefficients $(r), P$-values, adjusted $P$-values, and $q$ values were calculated in Prism. $P$-values were adjusted for multiple comparisons using Holm-Sidak $(\alpha=0.05)$. The false discovery rate (FDR) of $\mathrm{q}$ was calculated at $0.5 \%, 1 \%$, and $5 \%$. Correlation analyses with a sample size of 44 had $80.7 \%$ power $(\boldsymbol{\alpha}=0.05)$ to distinguish correlation coefficients that differ by 0.4 standard deviation units $\left(\mathrm{G}^{\star}\right.$ Power 3.1.9.4).

\section{Genetic analysis}

Sequence retrieval and multiple sequence alignment. SARS-CoV-2 reference sequences were downloaded from GISAID EpiCoV and combined with our Uruguayan study sequences in MEGA v.5.2 software, also used for sequence quality analysis, capping, and data refinement, if applicable [16]. Sequence alignments were performed using MAFFT v.7.471, FFTNS-2 method [17]. Highlighter analyses were performed on MAFFT-aligned full SARS-CoV-2 sequences from our Uruguayan study cohort with reference sequence Wuhan-Hu-1 as a master using the Highlighter tool provided by the Los Alamos HIV sequence database [18].

\section{Inference of a time-scaled phylogeny}

To infer our SARS-CoV-2 time-scaled phylogenetic tree, we selected global reference sequences used for the Nextstrain analysis specific for South America as of August $6^{\text {th }}, 2020$. This dataset consisted of 1,747 sequences sampled between December $26^{\text {th }}, 2019$ and July $17^{\text {th }}$, 2020, from Africa (40), Asia (194), Europe (112), North America (45), Oceania (17), and South America (128). We added 74 SARS-CoV2 Uruguayan sequences to generate an initial dataset containing 1,821 viral whole-genome sequences (Table S2). Using the Nextstrain metadata to identify the accessions of interest, we then downloaded the latest whole-genome sequence alignment from the GISAID database.

We aligned the whole genome sequences using MAFFT v.7.471 [17] and manually edited these by trimming the 5' and 3' untranslated regions and removing any gap only sites and low-quality sequences. This resulted in one low-quality Uruguayan sequence being removed, and a total of 73 remaining. The manually-edited alignment was then used to construct a maximum likelihood tree with ultra-fast bootstraps of 1,000 replicates in IQ-TREE v.2.0.3 [19], using the GTR+F+I nucleotide substitution model selected by Bayesian information criterion using model test implemented in IQ-TREE. TempEst [20] was used to check for outlier sequences in the tree resulting in the removal of a further ten sequences, to make up a final data set of 1,810 sequences. The tree was dated using TreeTime v.0.7.6 [21], specifying a clock rate of $8 \times 10^{-4}$ substitutions per site per year to replicate the original Nextstrain workflow analysis as faithfully as possible.

\section{Phylogeography analyses}

To obtain an estimate of the number of independent introductions of SARS-CoV-2 into Uruguay, we performed a preliminary phylogeography analysis using the asymmetric rates discrete diffusion model implemented in BEAST v.1.10.4 [22], adopting a fixed tree approach [10]. This approach greatly reduces the computational time required to perform the analyses by annotating the phylogeography analyses onto a fixed time-scaled phylogenetic tree. Our model considered two discrete ancestral location states, i.e. Uruguay and non-Uruguay, and specified a Markov chain Monte Carlo (MCMC) length of 1 
million steps, sampling every 200 steps to produce a posterior distribution of trees containing 5,000 trees. The time-scaled maximum clade credibility (MCC) tree from the discrete model phylogeography analysis conducted in BEAST was then identified using TreeAnnotator, available as part of the BEAST package and visualized in FigTree v.1.4.4 [23]. The BEAST log files were inspected for convergence using Tracer v.1.7.1 [24]. All model parameters achieved effective sample size (ESS) values $>200$ indicating sufficient mixing and convergence to stationary.

To estimate the potential regional source(s) of the independent introductions into Uruguay, we then replicated this phylogeography analysis, but this time considered seven discrete ancestral location states, including Uruguay, Africa, South America, North America, Oceania, Asia, and Europe.

\section{Software scripts and visualization}

See Supplemental Methods.

\section{Results}

\section{Study population and clinical parameters}

A total of 44 diagnosed positive COVID-19 participants were included in this study, 25 men and 19 women with a comparable mean age (and range) of 54 (15-92) and 59 (24-89) years, respectively. Sixty eight percent of the participants did not require hospitalization, $18 \%$ were hospitalized or received in-home care ( $9 \%$ on ventilation and $5 \%$ on ICU), and $14 \%$ were deceased. Whereas the early COVID-19 positive cases in March were predominantly GISAID clade S infections, clade $\mathrm{G}$ viruses subsequently became dominant in April and May 2020. (Figure 1 A-C).

Our cohort's cases came from 15 neighbourhoods in the capital, Montevideo. The majority of the samples came from the central neighbourhoods of Cordón and Pocitos, where the two most significant outbreaks within our cohort occurred (Figure 1B and Figure S1). Only two participants (from the Montevideo neighbourhoods Pocitos and Prado) reported a possibility of travel-related infection after returning from Japan.

\section{Diverse SARS-CoV-2 mutation profiles with increased prevalence of spike D614G variants and associated mutations in the evolving epidemic}

The SARS-CoV-2 genetic variants in our study group are very diverse and comprise sequences from GISAID clades S, V, G, GH, and GR (Figures 1A and 2A, Table S1). We found 446 mutations in our Uruguayan study sequences compared to the reference Wuhan-Hu-1 sequence [25], including three gaps. 313 were synonymous (non-amino acid changing) single nucleotide polymorphisms (SNPs), scattered across 60 positions, and 130 were non-synonymous (amino acid-changing), scattered across 32 positions of the open reading frames (Figure 2A, B). We observed between 5-12
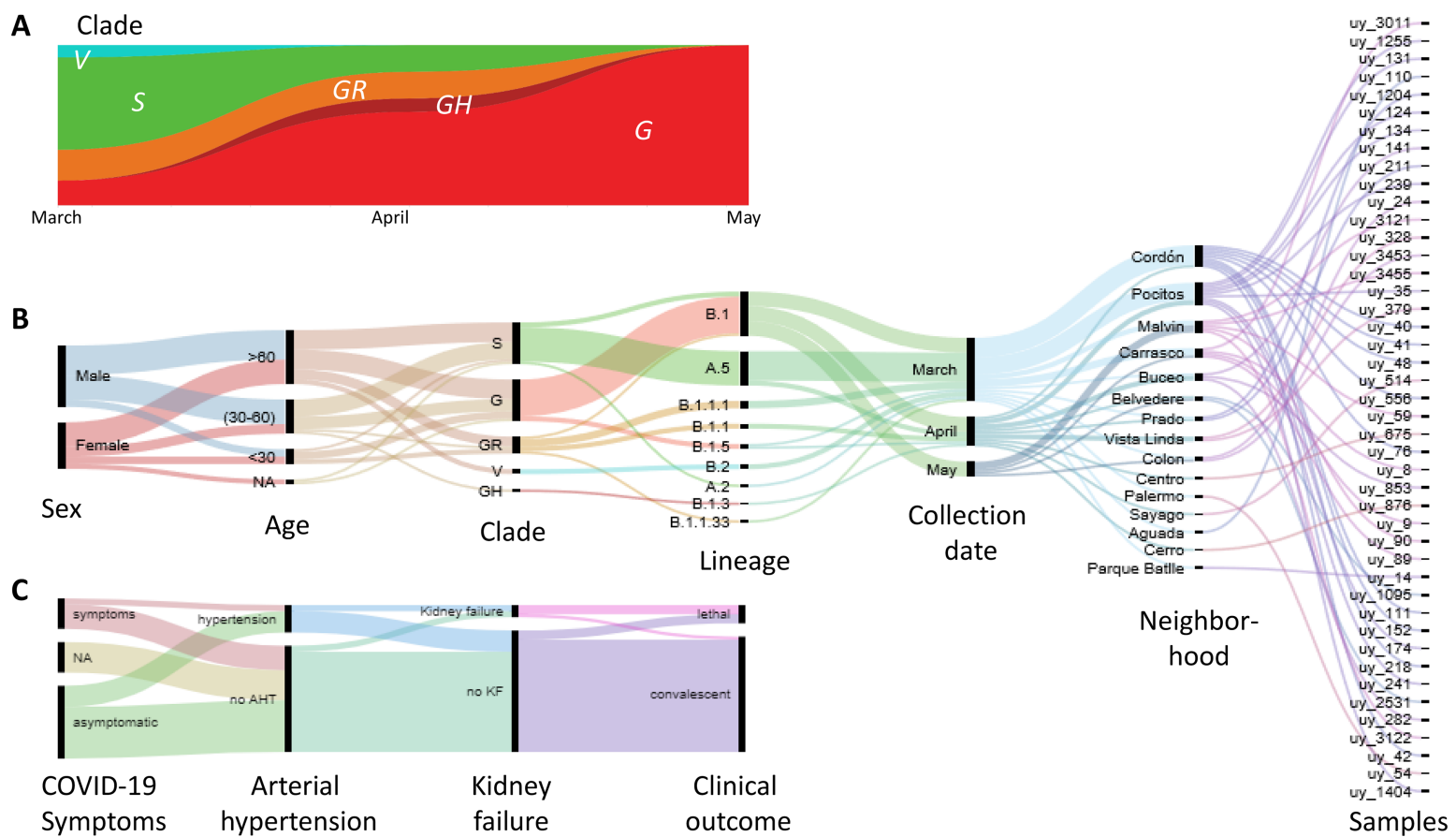

Figure 1. Virologic, demographic, and clinical parameters of the Uruguayan study cohort. (A) SARS-CoV-2 clade distribution over the $\sim 3$ month study period from March to May. (B) Demographic, virologic, and sample collection data are shown in a multicategorical alluvial diagram with the display of relatedness among features of two neighbouring nodes. (C) Clinical parameters of study participants, shown in alluvial representation as in B. 
SNPs resulting in 1-7 amino acid (AA) replacements per viral genome (Figure 2B, Figures S2 and S3). In chronologically sorted mutation/highlighter plots, various mutation patterns appeared in the first $2 / 3$ of the study period, whereas in the last $1 / 3$, the mutation patterns became more homogenous. In March and early April, ORF8 mutation L84S and the associated C8782 T SNP were most abundant ( $>1 / 3$ of sequences) (Figure 2A, C, Figures S2 and S3). Both mutations have become known as clade S-defining mutations (mostly in sublineage A.5) [26]. In addition, we found three more SNPs to be significantly associated, namely
C17470 T, C25521 T, and C26088 T, which collectively build a strongly significant, positive correlation cluster composed of five mutations (Figure S4). Interestingly, after April, most sequences belonged to clade G (sublineage B.1), defined by the spike protein's D614G mutation. $57 \%$ of our cohort's sequences contain the D614G mutation co-occurring with SNPs C241 T, C3037 T, and C14408 T, the latter causing the AA replacement P323L in the RNA-dependent RNA polymerase (RdRP) gene of nsp12 (Figure 2A, C, Figures S2 and S4). As known from other global studies [26], both clade S and G-associated mutations are largely
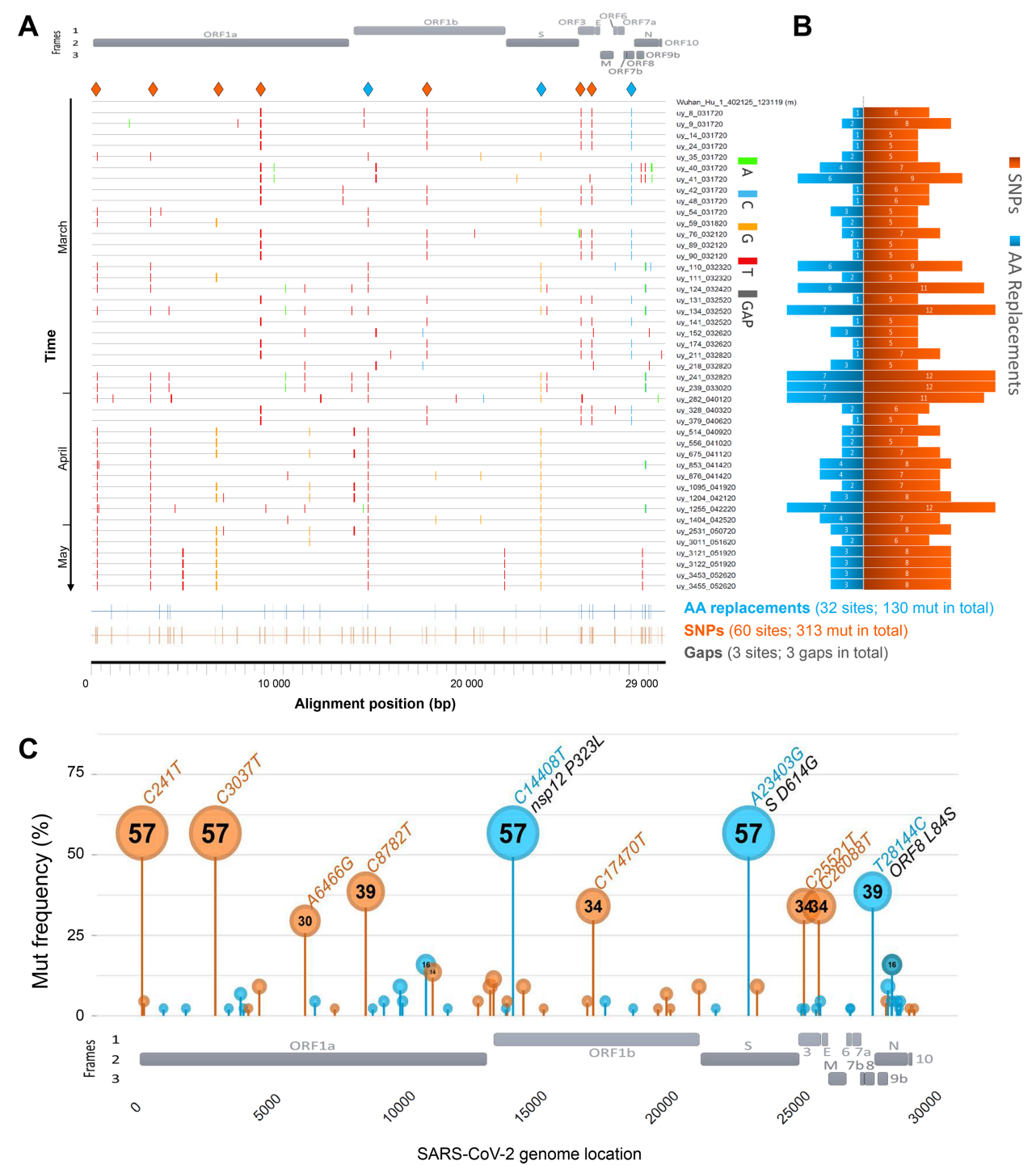

Figure 2. SARS-CoV-2 mutation patterns over time and mutation hotspots along the genome. (A) Highlighter plot showing mutations (mut) of Uruguayan study sequences compared to the reference Wuhan-Hu-1 sequence as master (on top). Mutations are shown as ticks, colour-coded according to the legend to the right. Study sequences are sorted along the y-axis according to sampling time, with the earliest sequences on top and most recent sequences at the bottom. A SARS-CoV-2 genome map with the three reading frames' coding genes is shown for orientation on top. All single-nucleotide polymorphisms (SNPs) are summarized in orange, and all SNPs resulting in amino acid (AA) replacements are summarized in blue at the bottom of the plot at the respective alignment positions. SNPs that are prevalent in $>30 \%$ of study sequences are highlighted by orange or blue (if AA replacement) diamonds on top of the plot. (B) Mirror bar chart summarizing the number of SNPs (orange) and AA replacements (blue) per study sample, aligned with the study sample IDs in A. (C) Lollipop plot summarizing the frequency of SARS-CoV-2 mutations in the Uruguayan study cohort $(n=44)$, using the same colour code as in B. A SARS-CoV-2 genome map with base-pair positions is shown at the bottom. The bubbles' $y$-coordinates indicate mutation frequencies, which are also shown inside the bubbles for mutations with $>10 \%$ prevalence. Mutation details are shown in orange (SNPs, bp mutation) or blue and black (AA replacements, bp mutation and aa mutation/affected protein region) for mutations $>30 \%$ prevalence. 


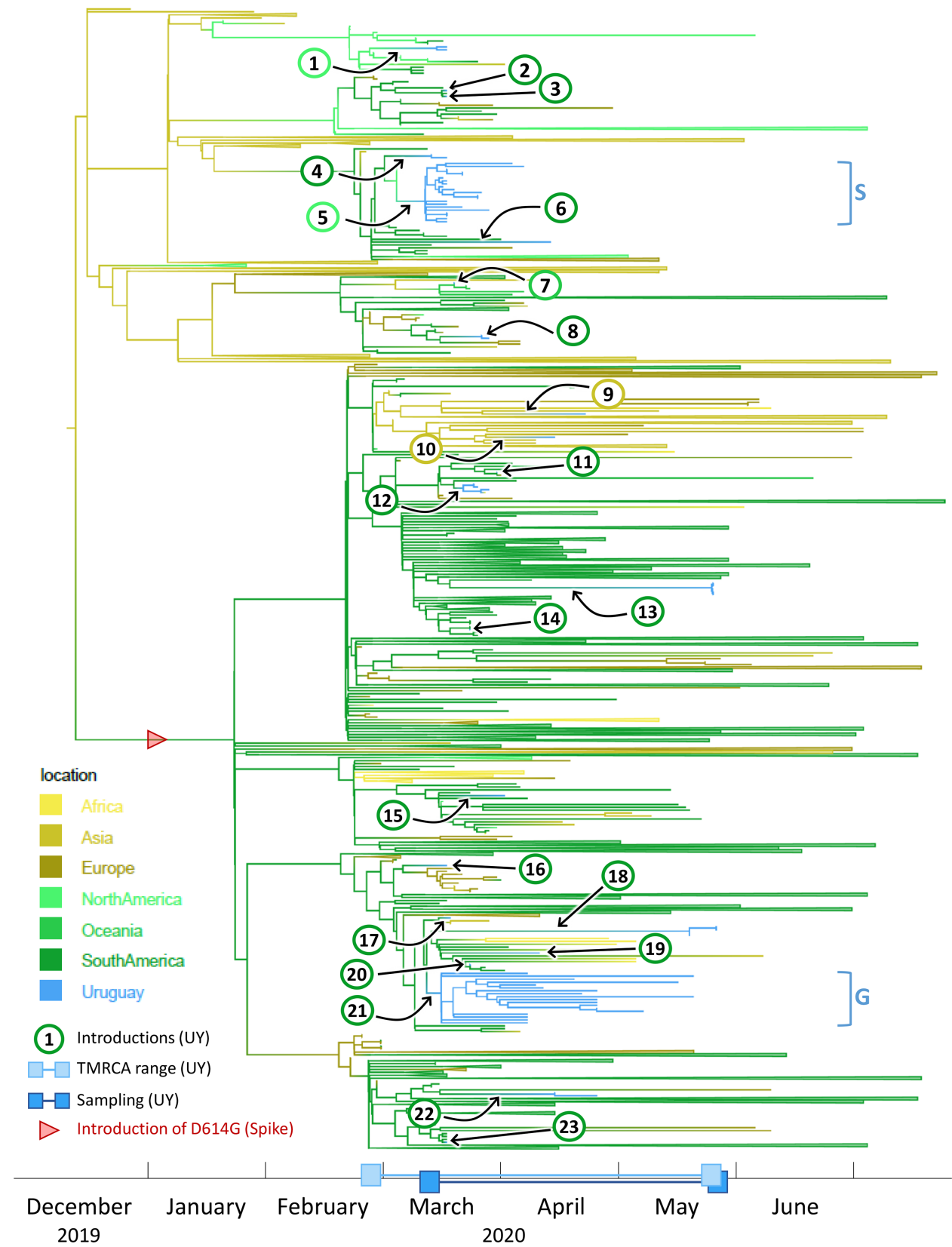

Figure 3. Time-scaled phylogenetic tree to identify the source regions of the sequences in the imported Uruguayan clusters. We employed a discrete state phylogeography diffusion model in BEAST with seven ancestral location states (Africa, Asia, Europe, North America, Oceania, South America, and Uruguay) to identify the most probable source locations for the sequences in the 23 previously identified international introductions into Uruguay. The branches of the trees are colour-coded according to each geographic region. A colour gradient along the branches indicates historic introduction events between locations. The introductions into Uruguay are highlighted by black arrows and circles with consecutive numbering according to the introduction event (colour-code of circle outline: probable source continent). The estimated time to the most recent common ancestors (TMRCAs) of Uruguayan (UY) sequences and their sampling period are indicated as ranges along the $x$-axis timeline. Branches that are not involved in introduction events are collapsed to facilitate visualization. The introduction of the spike D614G mutation is indicated by a red arrowhead. The two major Uruguayan clades are highlighted by brackets, and GISAID clades are indicated.

exclusive, resulting in strongly inverse correlation clusters (Figure S4).

\section{Phylogenetic assessment of the regional SARS- CoV-2 outbreak}

To determine phylogenetic and epidemiologic characteristics of the Uruguayan SARS-CoV-2 outbreak, we performed a comprehensive set of phylogenetic analyses, including maximum-likelihood trees, haplotype networks, Nextstrain-based phylogenetic placements, and Bayesian phylogeographic analyses using BEAST (Figures 3 and 4, Figures S5-S8). Focusing on all available Uruguayan SARS-CoV-2 sequences that passed our internal and GISAID's quality assessment $(n=73)$, we observed an intermixing of our (44) and other (29) Uruguayan study sequences, both in maximum-likelihood IQ trees and in genetic-distance-based haplotype networks (Figure S5). Consistent with the mutational analysis 

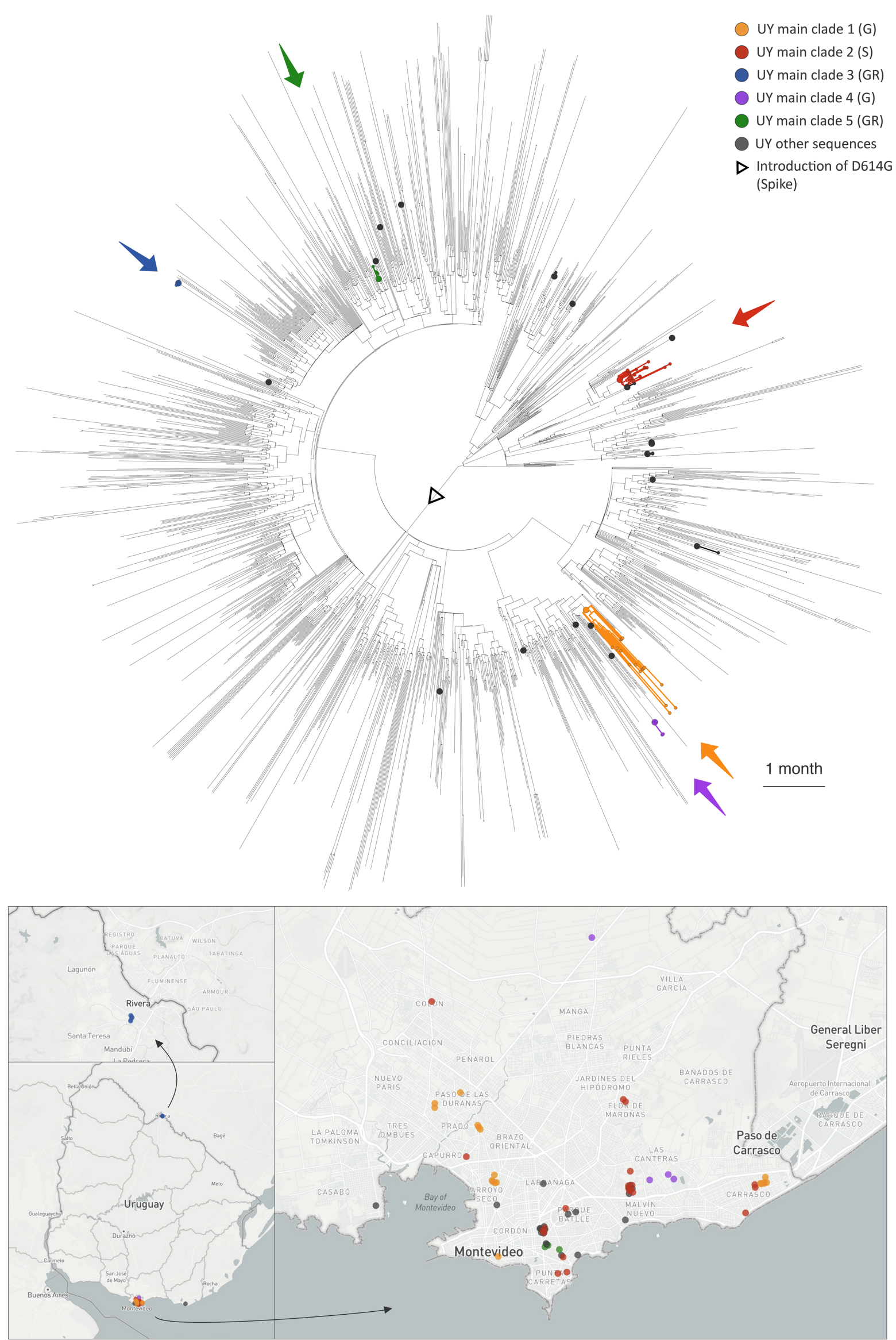

Figure 4. Visualization of the evolutionary relationships and spatial distribution of SARS-CoV-2 samples in the five Uruguayan clusters. A time-scaled maximum clade credibility tree (MCC) was generated by the discrete phylogeographic analysis of 1,810 SARS-CoV-2 genomic sequences. Uruguayan sequences are shown as coloured circles, both in the phylogenetic tree and in the Uruguayan maps. The five main Uruguayan clusters are colour-coded according to the legend (clades indicated in brackets). The remaining Uruguayan sequences, which are based on introduction events that did not form subsequent transmission chains within Uruguay, are shown as grey circles. 


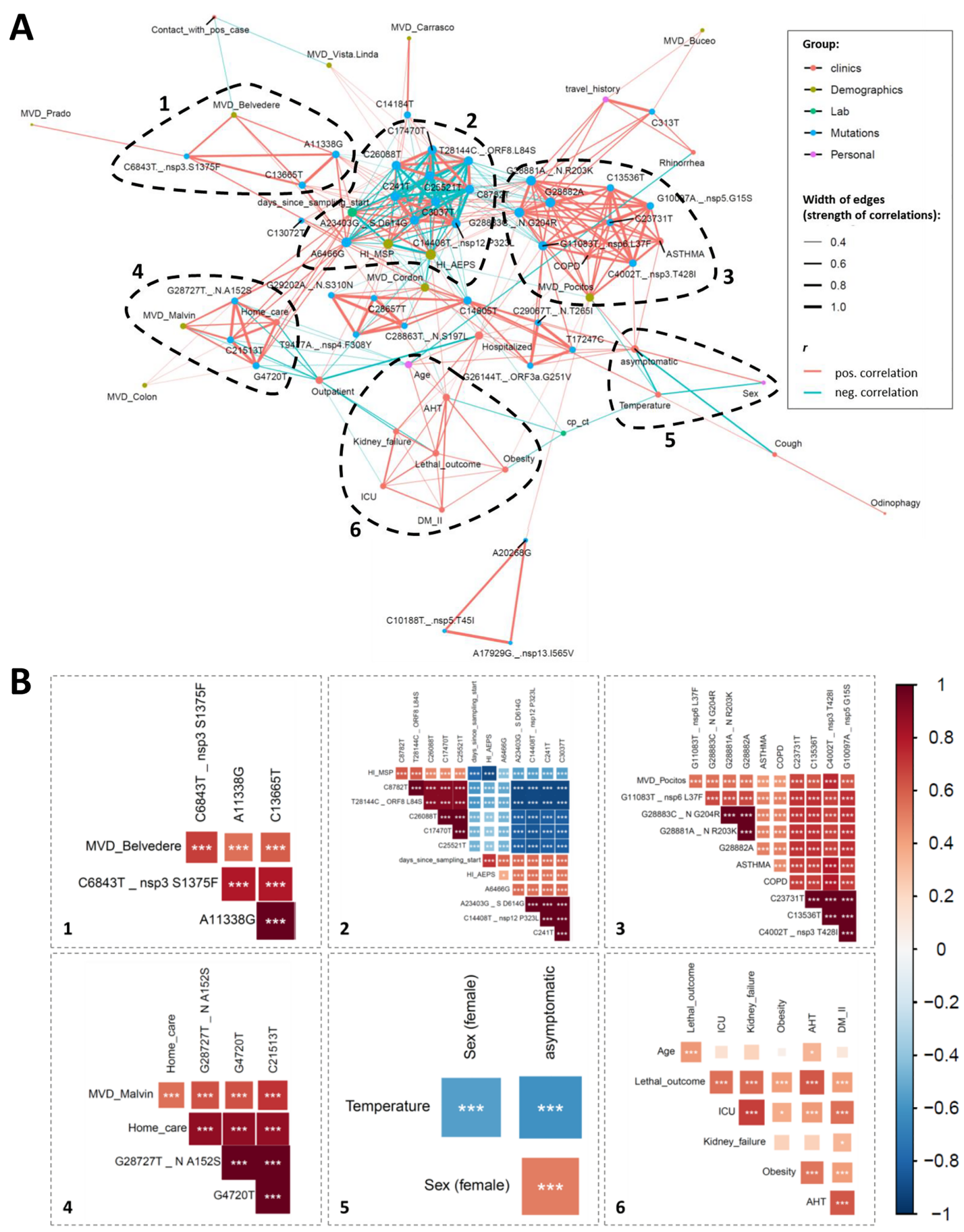

Figure 5. Correlation network analysis of virologic, demographic, and clinical parameters among Uruguayan study samples/participants. (A) In the correlation network plot, nodes represent clinical, demographic, laboratory, mutational, and personal parameters, and red and blue edges represent positive and negative correlations between connected parameters, respectively. Only significant correlations $(P<0.05)$ are displayed between parameters with at least two positive events. Edge width corresponds to the strength of the correlation. Nodes are colour-coded based on the grouping in clinical, demographic, laboratory, mutation, or personal parameters according to the legend to the upper right, and node size corresponds to the degree of relatedness of correlations. The six most prominent mixed correlation clusters are encircled with dashed lines and shown in greater detail as correlograms in the dashed boxes with matching numbers (1-6). (B) In the correlograms, squares are sized and colour-coded according to the magnitude of the correlation coefficient $(r)$. The colour code of $r$ values is shown to the right (red colours represent positive, blue colours negative correlations between two parameters). Asterisks indicate statistically significant correlations $\left({ }^{*} P<0.05,{ }^{* *} P<0.01,{ }^{* * *} P<0.005\right)$. Correlation analysis was done using nonparametric Spearman rank tests. MVD: Montevideo, $\mathrm{HI}$ : healthcare institution, ICU: intensive care unit, AHT: arterial hypertension, DM II: diabetes mellitus type II, COPD: chronic obstructive pulmonary disease.

of our internal data set (Figure 2), the phylogenetic analysis of the publicly available Uruguayan sequences reveals a predominance of clades $S$ and $G$
(G, GH, and GR), the former occupying most of the upper half of the maximum-likelihood tree (Figure S5A) and the right half of the haplotype 
network (Figure S5B), the latter the respective opposite halves, highlighted by green and red arrows for spike D614G and ORF8 L84S key mutations, respectively. The allocation of neighbourhood data on the phylogenetic tree indicated regionally clustered appearances of phylogenetically related viruses, as most evident for Carrasco, Pocitos, Malvin, Reducto (all in Montevideo), and Rivera (Figure S5A).

\section{Phylogeographic BEAST analysis reveals 23 introductions into Uruguay, mostly from surrounding South American countries, resulting in five clusters}

To assess global introductions and the regional spread of SARS-CoV-2 in Uruguay, we performed discrete phylogeographic analysis using BEAST with all 73 Uruguayan sequences, complemented with 1,737 global reference sequences, based on the global subsampling dataset suggested by Nextstrain (Table S2). Genetic distance-based haplotype networks indicated genetic relationships of Uruguayan sequences with those from other South American countries, Europe and Asia (Figure S6).

By explicitly considering the time and sampling locations of our sequences, BEAST analyses revealed further important details about the evolutionary relationships of our sequences. The time-scaled maximum clade credibility tree (MCC) generated by the discrete phylogeographic analysis of our 1,810 SARS$\mathrm{CoV}-2$ sequences is presented in Figure S7 and shows a minimum of 23 independent introductions of the SARS-CoV-2 virus occurred. Collectively, these introduction events included representatives from seven of the GISAID clades (G, GH, GR, L, O, $\mathrm{S}$, and V) circulating worldwide and all were imported to the capital city Montevideo except for one imported to Rivera.

The results of the discrete phylogeography analysis we performed that considered seven ancestral state locations further revealed that 18 of the 23 independent introductions are inferred to have originated from other South American countries. The remainders include two independent introductions of GISAID clade GR viruses from Asia, two from North America, and one clade V virus from Oceania (Figure 3). The viral sequences from the only two participants in our cohort that reported a possibility of travel-related infection after returning from Japan are inferred to have been imported from Asia and grouped on the tree within separate clades of Asian sequences. The estimated time to the most recent common ancestor (TMRCA), represented by the age of the root node of the entire tree, is in mid-December $2019\left(9^{\text {th }}-21^{\text {st }}\right.$ of December $)$, which is in agreement with the estimated origin of the pandemic in the Hubei Province in China, sometime between October and December, and the first contracted case in China recorded in mid-November [27-30].

Only five of the 23 independent virus introductions into Uruguay resulted in monophyletic clades with more than two sampled sequences in the country. These clades comprised 21, 18,5, 4, and 3 sequences, respectively (Figures 3 and 4, Figure S8), suggesting that these viral outbreaks were maintained by community transmission once introduced into Montevideo.

To investigate the timing of the introduction of the viruses that founded these five main clades circulating in Montevideo, we estimated the time of their most recent common ancestor (TMRCA), acknowledging that the actual introduction events likely occurred even before the corresponding TMRCAs.

The TMRCA of the first main clade of 21 sampled sequences, highlighted in red in Figure 4, was estimated to fall between the $2^{\text {nd }}$ and $5^{\text {th }}$ of March, 2020 and involved the importation of a GISAID clade $S$ virus. Viruses within this transmission cluster were restricted to Montevideo, where they were distributed among nine of the local neighbourhoods, including two hospitals and one research institute (Figure S8). A North American sequence from Mexico was positioned basally to this clade on the tree identifying this country as the most plausible source location.

The TMRCA of the second main clade, which comprised 18 virus sequences, highlighted in yellow in Figure 4 , was estimated to fall between the $13^{\text {th }}$ and $17^{\text {th }}$ March 2020 and involved the import of a GISAID clade $\mathrm{G}$ virus. Viruses within this transmission cluster were restricted to the city of Montevideo, where they were distributed among nine neighbourhoods and included samples from two nursing homes and one hospital (Figure S8). The viral sequences in this clade were inferred to have a South American origin.

The TMRCA of the third main clade of five sampled sequences, highlighted in blue in Figure 4 and corresponding to a GISAID clade GR, was estimated to fall between March $20^{\text {th }}$ and May $26^{\text {th }}, 2020$. This transmission cluster consisted of five viruses from the Hospital de Rivera in Rivera, a small city situated on the border with Brazil (Figure S8). This clade was inferred to have originated in South America and groups with a sequence from Brazil on the MCC tree suggesting this was the source location for this viral introduction.

The TMRCA of the fourth main clade with four sampled sequences, highlighted in purple in Figure 4 , was estimated to fall between March $14^{\text {th }}$ and May $20^{\text {th }}, 2020$ and involved the introduction of a GISAID clade G virus into Montevideo (Figure 4). This clade comprised four viruses from within two Montevideo neighbourhoods (Figure S8). The virus responsible for this introduction was also inferred to have originated in South America.

The TMRCA of the fifth main clade of three sequences, highlighted in green in Figure 4, was 
estimated to have occurred between the $22^{\text {nd }}$ and $24^{\text {th }}$ of March, 2019, and involved the introduction of a GISAID clade GR virus into Montevideo. This clade comprised three viruses from within a single Montevideo neighbourhood (Figure S8). Collectively, sequences from the four main clades described above were sampled between March and May 2020 and were distributed among 17 of the 57 neighbourhoods or barrios in Montevideo.

All of these five independent introduction events that formed sustained transmission chains identified here were estimated to have occurred close to the time of the first officially diagnosed case in Uruguay on March $13^{\text {th }}, 2020$ and the putative date of origin of the pandemic in Uruguay on March $7^{\text {th }}$, which was thought to be introduced by a single female traveller who arrived in Montevideo on a flight from Italy and subsequently attended a wedding reception in the city that was attended by over 500 guests.

\section{Distribution of SARS-CoV-2 within Uruguay}

Within these five clades we identified a total of ten sequence clusters (sequences from the same institution that group together on the tree), spread across six of the seven health institutions from which we had more than one sample (Figure S8). These included one cluster of five GISAID clade GR sequences in the Hospital de Rivera (red dots), two clusters of two clade G sequences in the Hospital Vilardebó (green dots), three clusters each comprised of two clade $S$ sequences in the Institut Pasteur (brown dots), and two clusters from the Asociación Española Primera en Salud (blue dots) comprising two $S$ and two $G$ clade sequences (Figure S8).

\section{Clinical correlations separate from mutational correlation clusters}

The availability of study participants' clinical and demographic data combined with mutational data of the infecting SARS-CoV-2 viruses enabled us to perform comprehensive correlation analyses (Figures 5 and 6, Figures S9-S11). Overall, Spearman rank correlation analyses revealed six prominent correlation clusters of significant positive or mixed correlations (Figure 5, Figure S9). Four of the highlighted clusters in Figure 5 (clusters 1-4) are dominated by mutations that form mixed clusters with demographic parameters such as sampling location or treating healthcare institution and a few other parameters. Clusters 5 and 6 are different in forming separate clinical correlation clusters together with the parameters "sex" (cluster 5) or "age" (cluster 6) without essential associations to virus mutations. Cluster 5 reveals a significant association of female sex with clinically asymptomatic courses of the disease and a lower risk of developing fever. Cluster 6 indicates a network of positive correlations among age, lethal outcome, and five clinical parameters. In addition to the highlighted clusters, we observed some smaller clusters, mainly composed of mutations. The tight network of positive clinical correlations and a more outspread correlation network of clades with regional appearances and selected demographic parameters are shown in greater detail in Figure 6A. Specifically, statistical analyses of lethal outcome as study parameter revealed significant positive correlations with arterial hypertension (AHT), kidney failure and ICU admission complemented by borderline-significant associations with additional clinical parameters (hospitalization, diabetes mellitus II, and obesity) and age, but no association with any specific mutation (Figure 6B, Figure S10). Accordingly, the spike D614G mutation and clade G-related viruses, in consequence, are not associated with any clinical parameters, severity, or lethality. D614G only correlates with co-occurring/ inversely occurring mutations, treating healthcare institutions, and time since sampling started (Figure 6C, Figure S11). Fatality rates among clade G, GR, and S-infected individuals were comparable at $18 \%$ (3/17), $14 \%(1 / 7)$, and $12 \%(2 / 17)$, respectively.

\section{Discussion}

The Uruguayan epidemic is characterized by an early clade $S$ dominance that was subsequently replaced by clade $G$ variants (Figures 1 and 2), which matches other South American countries (e.g. Chile) [31] and the global trend $[26,32,33]$. Uruguayan clade $S$ viruses are characterized by the key mutations T28144 C, causing the AA replacement L84S in ORF8, and C8782 $\mathrm{T}$, in agreement with global clade $\mathrm{S}$ strains [26]. In our data set, we observed three additional co-occurring SNPs in ORF1b and ORF3 that were present in 15 out of 17 clade S variants, i.e. C17470 T, $\mathrm{C} 25521 \mathrm{~T}$, and C26088 T. These mutations are less common and are presumably characteristic of the regional outbreak. Further studies need to show whether this subclade will be fixed in regional and/ or supra-regional epidemics, and whether founder effects or functional features accounted for the early clade $\mathrm{S}$ dominance over the original clade as well as the subsequent fluctuating prevalence and decline. According to the CoV-GLUE database, ORF8 L84S is the 8th most prevalent $\mathrm{AA}$ replacement to date [34]. After a controversial debate about the ancestry of $\mathrm{L}$ and $\mathrm{S}$ types and the functional impact of L84S [35-37], the still limited amount of data indicates that L84S might confer selection advantage and render the virus more virulent based on destabilizing the immuno- and replication-modulatory protein ORF8 and mitigating binding of ORF8 to human complement C3b [35-38]. 
A

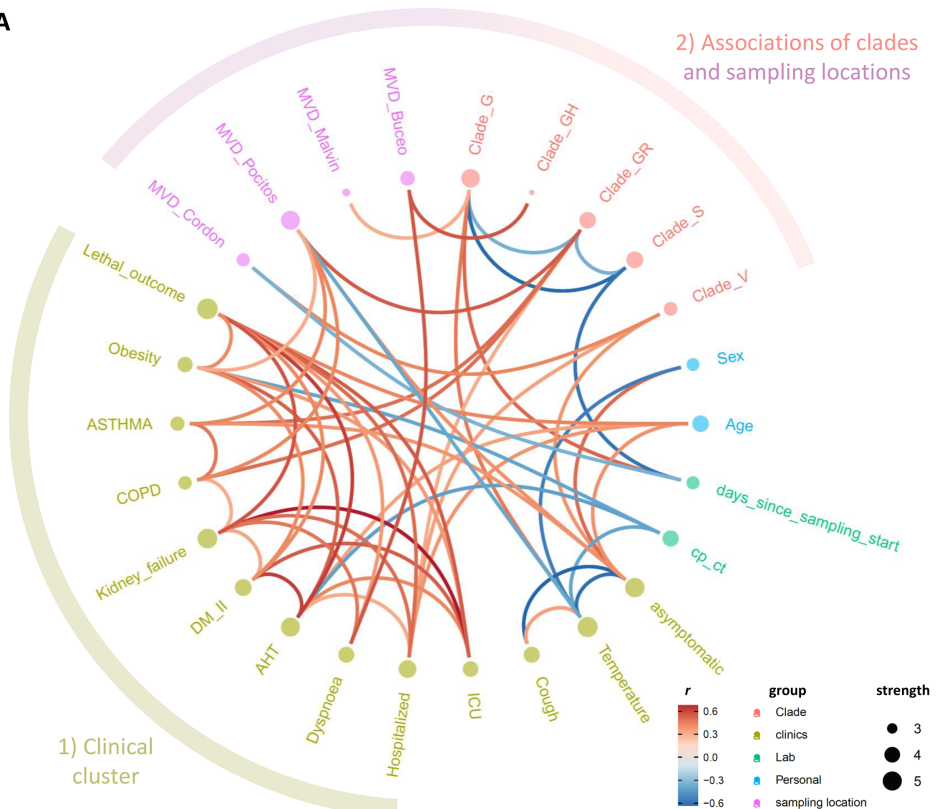

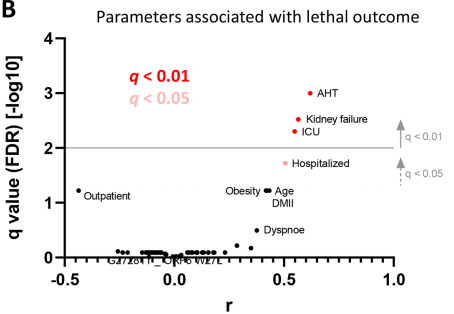

C

Parameters associated with D614G mutation

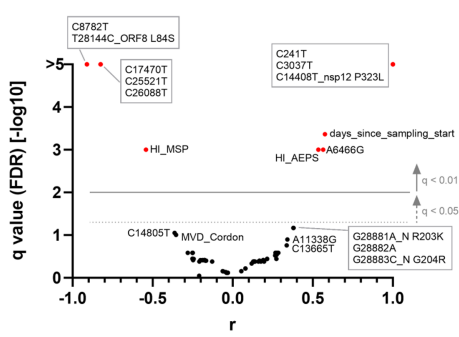

Figure 6. Clade and clinical correlation analysis and study parameters associated with lethal outcome and spike D614G mutation. (A) In the edge bundling correlation plot, red and blue edges represent positive and negative correlations between connected parameters, respectively. Only significant correlations $(P<0.05)$ are displayed, and all parameters have at least two positive events. Nodes are colour-coded based on the grouping into clades, clinical, laboratory, neighbourhood, and personal data according to the legend at the bottom. Node size corresponds to the degree of relatedness of correlations. Surrounding circle segments highlight a strong clinical cluster and a less pronounced clade/sampling location cluster. (B) Volcano plot of parameters associated with lethal outcome. The full data set (see Figure 5 and Figure S9) was screened for parameters with false discovery rates (FDR) of $q<0.01$ (red, considered significant) and $0.01<q<0.05$ (pale red, considered borderline significant). (C) Volcano plot of parameters associated with the presence of D614G mutation in spike proteins of study participants' infecting SARS-CoV-2 viruses. The same display was used as in B. Correlation analysis was done using nonparametric Spearman rank tests. All parameters that achieved $P<0.05$ correlations are labelled. Parameters inheriting the same dot are boxed. MVD: Montevideo, HI: healthcare institution.

End of March/early April 2020, we observed a subsequent switch in dominance from clade $\mathrm{S}$ to clade $\mathrm{G}$ variants (G, GR, and GH) (Figures 1 and 2). It positioned Uruguay somewhere in the middle in the asynchronous transition process from spike D614 to G614 virus predominance, i.e. between the early European and the mostly late Asian countries [32,33]. Diverse structural and functional assays strongly suggest that the spike D614G mutation renders SARS-CoV-2 more infectious by stabilizing its structure, i.e. through impact on the, compared to SARS-CoV-1, even more fragile metastable SARSCoV-2 spike protein, thus reducing the shedding of the S1 subunit. Furthermore, D614G triggers higher spike numbers on the virion surface and induces a more open, receptor-binding domain (RBD)-up spike conformation toward a receptor-binding and fusion-competent state [33,35,36,39-42]. In D614G spikes, binding to the angiotensin-converting enzyme 2 (ACE2) receptor is not increased, and SARS-CoV-2 viruses do not acquire D614G escape mutations in vitro under neutralizing antibody immune pressure $[39,43]$. Instead, D614G increases neutralization susceptibility of SARS-CoV-2, which assures high sensitivity to vaccination-induced neutralizing antibodies $[44,45]$.
Although D614G serves as the clade G-defining mutation with likely effects on virus infectivity/transmissibility, D614G is governed by a very strict coappearance with C241 T, C3037 T, and C14408 T, both in Uruguayan and global $\mathrm{G}$ variants (Figure 5, Figure S5) [26]. Notably, in addition to the D614Gcausing A23403 G mutation in spike, C14408 T is responsible for the AA replacement $\mathrm{P} 323 \mathrm{~L}$ in the RdRp gene. Based on their central roles in viral entry and replication, their co-evolution is of particular interest, and a mutual contribution to the selective advantage of G-haplotypes is assumed [33]. Interestingly, none of the viruses harbouring a single clade $G$ mutation prevailed to achieve epidemiological relevance, e.g. D614G alone or P323L alone have $\leq 0.3$ global prevalence, whereas D614G and P323L together have $770 \%$ global prevalence as of August 2020 [33]. $\mathrm{P} 323 \mathrm{~L}$, although not located in the active centre, possibly influences RdRp fidelity through allosteric effects at the nsp12 interface with the nsp8 cofactor and might increase the viral mutation rate $[33,38,46]$. Thus, the strong correlation patterns between key mutations in our Uruguayan data set, mirroring global patterns, allows us to hypothesize that coupled mutations, such as D614G in spike and P3233L in RdRp might synergize for the epidemiological success 
of the virus. It may allow a fine balance between efficient transmission (e.g. by D614G, even in asymptomatic cases) and limited clinical presentation (e.g. by $\mathrm{P} 323 \mathrm{~L}$, decreasing the production of viral RNA) to eventually attenuate an aggressive virus that, as shown for MERS and SARS-CoV-1, is more vulnerable to viral clearance with lack of long-term epidemiological success. Further studies are needed to determine how the increasing diversity of mutation patterns influence the fitness and reproduction of viral populations, the susceptibility/evasion to immune responses and treatment, and how these mutations are selected in the human body or during transmission.

Beyond the functional relevance of emerging and transmitted mutations, they serve as a fine tool to dissect population phylodynamics, transmission chains and epidemiologic clusters. The number of independent introduction events into a particular country as a proportion of the total number of sequences in the data set is considered a rough measure of the relative influence of intercontinental and international travel on the subsequent epidemiological dynamics within that country. For Uruguay, with 23 identified independent migration events out of a total of 73 viral sequences in our dataset, this proportion is relatively low if compared to other countries such as Belgium (331/740) [10] but higher than others like Brazil $(>100 / 490)$ [8]. It possibly indicates that the relative influence of intercontinental and international travel has been less important in driving the dispersal dynamics of the Uruguay outbreak compared to other, larger or more connected countries like Belgium. Data from other South-American countries besides Uruguay, Brazil, and Chile are scarce [31,4750]. The town of Rivera, situated on the border with Brazil, has been a main concern for the government and many outbreaks occurred along the border that were rapidly brought under control. In line with our BEAST results that suggested a single transmission from Brazil as the main source of the Rivera infections, the first Rivera outbreak was reported to have begun when a COVID-19-positive Uruguayan was diagnosed on May $7^{\text {th }}, 2020$. Our BEAST analysis strongly supports the former hypothesis from the Uruguayan Government and Ministry of Health (MSP) that a local metallurgic worker who used to travel to Brazil every day had been infected with SARS-CoV-2 in Brazil and introduced this strain to Rivera $[51,52]$.

There are two main reasons why the extent of the geographical distribution and the density of viruses in each neighbourhood within Montevideo and Rivera, responsible for the five main clades of SARSCoV-2 circulating in Uruguay (Figure 4, Figure S8), represent an underestimate of the true values of both these variables. First, our 73 Uruguayan sequenced viral genomes represent only a relatively small fraction of the total number of infections that occurred in the actual outbreak seeded by these viruses, with estimates obtained from contact tracing efforts suggesting that collectively these viruses infected at least 364 individuals [2]. Secondly, 39 (53\%) of our Uruguayan samples were either collected in hospitals (Hospital de Rivera, Asociación Española - AEPS, or Hospital Vilardebó) where the infected patient was treated or where the infection was acquired, in nursing homes, or in research institutes (Institut Pasteur) where samples were processed. In these cases, the home address of the patient samples is not publicly available. This precluded the adoption of the continuous diffusion phylogeography model [53] that makes use of the actual geographic coordinates of the samples to infer the transmission links among the sampled locations in the various Montevideo neighbourhoods, and instead, limited our analysis to describe the spatial relationships among the sampled SARS-CoV-2 sequences.

Our discrete phylogeographic analysis provided a new perspective to the believed origin of the Uruguayan SARS-CoV-2 outbreak from overseas by a single traveller returning from Europe [54,55]. While overall similarities of Uruguayan sequences with European and Asian sequences were observed in mutation patterns and genetic distance-based haplotype networks, our phylogeographic analyses using BEAST indicate that Uruguayan introductions that resulted in outbreaks were mostly restricted to neighbouring South American countries (Figure 3), which stands in contrast to the suggestions of a recent preprint article [7]. Instead, our data support the idea that the outbreaks that were seeded after return from overseas travel were contained successfully through social distancing, mask wearing, rigorous testing, contact tracing, and partial lockdown [2].

Having determined the regional SARS-CoV-2 mutation patterns and phylogeographic spread, the question remained whether and to what extent genomic features are coupled to demographic and/or clinical parameters. Our correlation data revealed significant clusters of co-occurring or mutually excluding mutations with regionally accumulated appearances of clades/mutation clusters (Figures 4 and 5, Figure S5). In contrast, the large bulk of clinical parameters clustered separately without major influence from viral mutations (Figures 5 and 6, Figure S10), which is in line with a recent publication that reported no significant impact of genetic variation on clinical outcome [56]. More specifically, we studied pairwise correlations with the spike D614G mutation, which, because of perfectly matching mutation patterns, also represents correlation analyses for the RdRp P323L mutation or G-related clades (G, GR, and GH). In an FDR-adjusted analysis, the presence of D614G mutation was coupled to other viral mutations, treatment of the infected patients in a regional healthcare 
institution, and late sampling, but not to clinical parameters (Figures 5 and 6, Figure S11). There have been controversial reports of D614G being associated with higher fatality rates and/or severe illness in a few data sets $[57,58]$, whereas more recent data suggests no correlations of D614G with clinical outcome [33], the latter supported by our findings. Our analysis pointed at significant associations between lethal outcome and arterial hypertension, kidney failure, and ICU admission, which mirrors clinical studies on associated factors or predictors of disease severity/progression $[59,60]$.

In sum, our characterization of Uruguayan SARSCoV-2 phylogenetics, mutation patterns, and their correlation with demographic and clinical parameters did not identify critical viral attenuations or clinical peculiarities that can primarily account for the exceptionally well curbed regional COVID-19 epidemic [2]. It instead suggests that socio-epidemiologic mitigation strategies managed to curtail COVID-19 to restricted regional transmission clusters in Uruguay. The moderate case number of 73 sequences for phylogenetic and phylogeographic analyses, and 44 sequences for clinical correlation analyses, is a limitation of the present study. However, the analysis of almost $10 \%$ of the total number of recorded cases in Uruguay (73 of 789 reported COVID-19 cases in the entire country, May $\left.26^{\text {th }}\right)[12$ ] provides a representative picture, and follow-up studies are warranted to confirm the results.

We hope that these findings contribute to define the South American COVID-19 outbreak better, to optimize and develop efficient, fast, and low-cost mitigation strategies and diagnostic pipelines for Uruguay and other countries, and to assist physicians dealing with strategies for this and future emerging infections.

\section{Acknowledgments}

The authors thank all participants who agreed to participate in this study and the healthcare personnel in Uruguay for their dedication to COVID-19 patients' care. We wish to acknowledge the support of New York University's Data Services, Bobst Library, and, in particular, the expertise shared by Christopher Schwarz and Senior Academic Technology Specialist Denis Rubin in software script development. We also acknowledge the support of the NYU Langone Health High-Performance Computing resource and the Laura and Isaac Perlmutter Cancer Center, which partially supports the Genome Technology Center. We thank the scientists across the world who deposited SARS-CoV-2 sequences in GISAID, especially those who deposited 29 Uruguayan sequences that supplemented our 44 sequences. We would also like to thank Flavia Camacho for administrative assistance. VE1, AH, and RD conceived research goals, experiments, and analyses. GWH, BM, SS, VP, and RD performed formal analyses. VE1, RB, and $A H$ acquired funding for the project. PZ, CM, VP, NM, CB, SI, MF, VP, VE2, GM, AS, FR, MN, LP, SB, and MNZ performed experiments and/or were involved in sample acquisition. BM, MTM, $\mathrm{GWH}, \mathrm{SD}, \mathrm{AH}$, and RD developed methodologies, designed, and/or implemented computer codes. VE1, GWH, MTM, $\mathrm{SD}, \mathrm{RB}, \mathrm{AH}$, and RD supervised the research activity and validated the research output. GWH, BM, SD, VP, and RD prepared figures and tables. VE1, GWH, AH, and RD wrote the manuscript. All authors reviewed and edited the manuscript.

\section{Disclosure Statement}

No potential conflict of interest was reported by the author (s).

\section{Funding}

All the work at the Laboratorio de Biología Molecular AEPS was supported by internal funding from the Asociación Española Primera en Salud. SS was supported by the South African National Research Foundation. SD was supported by the Fonds National de la Recherche Scientifique (FNRS, Belgium). MTM was partially funded by the National Institutes of Health [grant number R35GM119703]. RD was partially supported by the National Institute of Allergy and Infectious Diseases of the National Institutes of Health [grant number R01AI122953]. AH, CM, and PZ were supported by the Genome Technology Center, and in part by the Cancer Center Support Grant from the National Cancer Institute of the National Institutes of Health [grant number P30CA016087] at the Laura and Isaac Perlmutter Cancer Center; Center for Scientific Review.

\section{ORCID}

Gordon W. Harkins (D) http://orcid.org/0000-0003-00418047

Natalia Mazza (1) http://orcid.org/0000-0002-9139-5313

Simon Dellicour (D) http://orcid.org/0000-0001-9558-1052

Adriana Heguy (D) http://orcid.org/0000-0002-2836-6683

Ralf Duerr (iD http://orcid.org/0000-0001-9569-9237

\section{References}

[1] CSSE. Center for Systems Science and Engineering (CSSE) at Johns Hopkins University 2020. Available from: https://gisanddata.maps.arcgis.com/apps/opsdash board/index.html\#/bda7594740fd40299423467b48e9 ecf6.

[2] Moreno P, Moratorio GA, Iraola G, et al. An effective COVID-19 response in South America: the Uruguayan Conundrum. medRxiv. 2020:2020.07.24.20161802.

[3] INE. Global Health Data Exchange Washington2020 [cited 2020 September 8]. Available from: http:// ghdx.healthdata.org/organizations/national-institutestatistics-uruguay.

[4] IMPO. Decreto No. 93/020: Declaracion de Estado de Emergencia Nacional Sanitaria como Consecuencia de la Pandemia Originada por el Virus COVID-19 (Coronavirus) Uruguay: Registro Nacional de Leyes y Decretos [Decree No. 93/020: Declaration of a state of national health emergency as a consequence of the pandemic originated by the COVID-19 virus (Coronavirus) Uruguay: National Registry of Laws and Decrees]; 2020 [cited 2020 September 4]. Available from: https://www.impo.com.uy/bases/ decretos/93-2020. Spanish. 
[5] IMPO. Decreto No. 104/020: Autorizacion del Ingreso al Pais Unicamente de Ciudadanos Uruguayos y Extranjeros Residentes Provenientes del Exterior Uruguay: Registro Nacional de Leyes y Decretos [Decree No. 104/020: Entry authorization to the country only for Uruguayan citizens and resident foreigners from abroad Uruguay: National Registry of Laws and Decrees]; 2020 [cited 2020 September 4]. Available from: http://www.impo.com.uy/bases/ decretos/104-2020. Spanish.

[6] SNE. Visualizador de casos coronavirus COVID-19 en Uruguay [Viewer of coronavirus COVID-19 cases in Uruguay 2020]; 2020 [cited 2020 September 15]. Available from: https://www.gub.uy/sistemanacional-emergencias/pagina-embebida/visualizadorcasos-coronavirus-covid-19-uruguay. Spanish.

[7] Salazar C, Díaz-Viraqué F, Pereira-Gómez M, et al. Multiple introductions, regional spread and local differentiation during the first week of COVID-19 epidemic in Montevideo, Uruguay. bioRxiv. 2020:2020.05.09.086223.

[8] Candido DS, Claro IM, de Jesus JG, et al. Evolution and epidemic spread of SARS-CoV-2 in Brazil. Science. 2020 Sep 4; 369(6508):1255-1260.

[9] Gonzalez-Reiche AS, Hernandez MM, Sullivan MJ, et al. Introductions and early spread of SARS-CoV-2 in the New York city area. Science. 2020 Jul 17;369 (6501):297-301.

[10] Dellicour S, Durkin K, Hong SL, et al. A phylodynamic workflow to rapidly gain insights into the dispersal history and dynamics of SARS-CoV-2 lineages. Mol Biol Evol. 2020 Nov 3; msaa284.

[11] Maurano MT, Ramaswami S, Zappile P, et al. Sequencing identifies multiple early introductions of SARS-CoV-2 to the New York city region. Genome Res. 2020 Oct 22;30(12):1781-1788.

[12] Uruguay Presidencia. COVID-19: Hay 129 casos activos en seis departamentos [COVID-19: there are 129 active cases in six departments]; 2020. Available from: https://www. presidencia.gub.uy/comunicacion/comunicacionnoticias/ informe-sinae-martes-26. Spanish.

[13] Hadfield J, Megill C, Bell SM, et al. Nextstrain: realtime tracking of pathogen evolution. Bioinformatics. 2018 Dec 1;34(23):4121-4123.

[14] MINISTERIO DE SALUD PÚBLICA. COVID-19 Vigilancia y diagnóstico laboratorial [COVID-19 surveillance and laboratory diagnosis]; 2020. Available from: https://www.gub.uy/ministerio-salud-publica/ sites/ministerio-salud-publica/files/documentos/ noticias/03_MSP_COVID_19_VIGILANCIA_ DIAGNOSTICO_FINAL.pdf. Spanish.

[15] MINISTERIO DE SALUD PÚBLICA. Plan Nacional de Contingencia para la Infección (COVID-19) por el nuevo Coronavirus (SARS CoV2) [National contingency plan for infection (COVID-19) by the new coronavirus (SARS CoV2)]; 2020. Available from: https:// www.gub.uy/ministerio-salud-publica/sites/minister io-salud-publica/files/documentos/noticias/01_MS P_COVID_19_PLAN_NACIONAL_CONTINGENC IA_GESTION_RESPUESTA.pdf. Spanish.

[16] Tamura K, Peterson D, Peterson N, et al. MEGA5: molecular evolutionary genetics analysis using maximum likelihood, evolutionary distance, and maximum parsimony methods. Mol Biol Evol. 2011 Oct;28 (10):2731-2739.

[17] Katoh K, Rozewicki J, Yamada KD. MAFFT online service: multiple sequence alignment, interactive sequence choice and visualization. Brief Bioinform. 2019 Jul 19;20(4):1160-1166.

[18] Los Alamos National Laboratory tools. Highlighter tool 2020. Available from: http://www.hiv.lanl.gov/.

[19] Nguyen LT, Schmidt HA, von Haeseler A, et al. IQTREE: a fast and effective stochastic algorithm for estimating maximum-likelihood phylogenies. Mol Biol Evol. 2015 Jan;32(1):268-274.

[20] Rambaut A, Lam TT, Max Carvalho L, et al. Exploring the temporal structure of heterochronous sequences using TempEst (formerly Path-O-Gen). Virus Evol. 2016 Jan;2(1):vew007.

[21] Sagulenko P, Puller V, Neher RA. Treetime: maximum-likelihood phylodynamic analysis. Virus Evol. 2018 Jan;4(1):vex042.

[22] Suchard MA, Lemey P, Baele G, et al. Bayesian phylogenetic and phylodynamic data integration using BEAST 1.10. Virus Evol. 2018 Jan;4(1):vey016.

[23] Rambaut A, Drummond AJ. Tracer v1.5. 2009.

[24] Rambaut A, Drummond AJ, Xie D, et al. Posterior Summarization in Bayesian phylogenetics using Tracer 1.7. Syst Biol. 2018 Sep 1;67(5):901-904.

[25] Wu F, Zhao S, Yu B, et al. A new coronavirus associated with human respiratory disease in China. Nature. 2020 Mar;579(7798):265-269.

[26] Mercatelli D, Giorgi FM. Geographic and genomic distribution of SARS-CoV-2 mutations. Front Microbiol. 2020;11:1800.

[27] Bryner J. 1st known case of coronavirus traced back to November in China 2020. Available from: https:// www.livescience.com/first-case-coronavirus-found. html.

[28] Nie Q, Li X, Chen W, et al. Phylogenetic and phylodynamic analyses of SARS-CoV-2. Virus Res. 2020 Oct 2;287:198098.

[29] van Dorp L, Acman M, Richard D, et al. Emergence of genomic diversity and recurrent mutations in SARSCoV-2. Infect Genet Evol. 2020 Sep;83:104351.

[30] Andersen KG, Rambaut A, Lipkin WI, et al. The proximal origin of SARS-CoV-2. Nat Med. 2020 Apr;26 (4):450-452.

[31] Castillo AE, Parra B, Tapia P, et al. Geographical distribution of genetic variants and Lineages of SARSCoV-2 in Chile. Front Public Health. 2020;8:562615.

[32] Korber B, Fischer WM, Gnanakaran S, et al. Tracking changes in SARS-CoV-2 spike: evidence that D614G increases infectivity of the COVID-19 virus. Cell. 2020 Aug 20;182(4):812-827.e19.

[33] Ilmjärv S, Abdul F, Acosta-Gutiérrez S, et al. Epidemiologically most successful SARS-CoV-2 variant: concurrent mutations in RNA-dependent RNA polymerase and spike protein. medRxiv. 2020:2020.08.23.20180281.

[34] CoV-GLUE. CoV-GLUE - Amino acid replacements 2020. Available from: http://cov-glue.cvr.gla.ac.uk/ \#/replacement.

[35] Wang R, Chen J, Gao K, et al. Characterizing SARSCoV-2 mutations in the United States. Res Sq. 2020 Aug 11.

[36] Liu Q, Zhao S, Hou Y, et al. Ongoing natural selection drives the evolution of SARS-CoV-2 genomes. medRxiv. 2020:2020.09.07.20189860.

[37] Chaw SM, Tai JH, Chen SL, et al. The origin and underlying driving forces of the SARS-CoV-2 outbreak. J Biomed Sci. 2020 Jun 7;27(1):73.

[38] Portelli S, Olshansky M, Rodrigues CHM, et al. COVID-3D: an online resource to explore the 
structural distribution of genetic variation in SARSCoV-2 and its implication on therapeutic development. bioRxiv. 2020:2020.05.29.124610.

[39] Zhang L, Jackson CB, Mou H, et al. The D614G mutation in the SARS-CoV-2 spike protein reduces S1 shedding and increases infectivity. bioRxiv. 2020:2020.06.12.148726.

[40] Li Q, Wu J, Nie J, et al. The impact of mutations in SARS-CoV-2 spike on viral infectivity and antigenicity. Cell. 2020 Sep 3;182(5):1284-1294.e9.

[41] Yurkovetskiy L, Wang X, Pascal KE, et al. Structural and functional analysis of the D614G SARS-CoV-2 spike protein variant. Cell. 2020 Oct 29;183(3):739751 e8.

[42] Mansbach RA, Chakraborty S, Nguyen K, et al. The SARS-CoV-2 spike variant D614G favors an open conformational state. bioRxiv. 2020:2020.07.26.21 9741.

[43] Baum A, Fulton BO, Wloga E, et al. Antibody cocktail to SARS-CoV-2 spike protein prevents rapid mutational escape seen with individual antibodies. Science. 2020 Aug 21;369(6506):1014-1018.

[44] Weissman D, Alameh M-G, de Silva T, et al. D614G spike mutation increases SARS CoV-2 susceptibility to neutralization. Cell Host Microbe. 2020 Dec 1: S1931-3128(20)30634-X

[45] Sahin U, Muik A, Derhovanessian E, et al. Concurrent human antibody and $\mathrm{T}_{\mathrm{H}} 1$ type $\mathrm{T}$-cell responses elicited by a COVID-19 RNA vaccine. medRxiv. 2020:2020.07.17.20140533.

[46] Pachetti M, Marini B, Benedetti F, et al. Emerging SARS-CoV-2 mutation hot spots include a novel RNA-dependent-RNA polymerase variant. J Transl Med. 2020 Apr 22;18(1):179.

[47] Castillo AE, Parra B, Tapia P, et al. Phylogenetic analysis of the first four SARS-CoV-2 cases in Chile. J Med Virol. 2020 Mar 29;92(9):1562-1566.

[48] Padilla-Rojas C, Lope-Pari P, Vega-Chozo K, et al. Near-complete genome sequence of a 2019 novel coronavirus (SARS-CoV-2) strain causing a COVID-19 case in Peru. Microbiol Resour Announc. 2020 May 7;9(19):e00303-20.

[49] Poterico JA, Mestanza O. Genetic variants and source of introduction of SARS-CoV-2 in South America. J Med Virol. 2020 May 13;92(10):2139-2145.

[50] Ramirez JD, Munoz M, Hernandez C, et al. Genetic diversity Among SARS-CoV2 strains in South America may impact Performance of molecular Detection. Pathogens. 2020 Jul 17;9(7):580.
[51] LaRed21. Primer caso autóctono de COVID-19 en Rivera: Hombre se habría contagiado en Brasil [First indigenous case of COVID-19 in Rivera: man would have been infected in Brazil]; 2020. Available from: https://www.lr21.com.uy/comunidad/1427746-prime r-caso-autoctono-de-covid-19-en-rivera-hombre-se -habria-contagiado-en-brasil. Spanish.

[52] Subrayado. Metalworker from Rivera, who works in Livramento, first autochthonous case of Covid-19 2020. Available from: https://www.subrayado.com. uy/obrero-metalurgico-rivera-que-trabaja-livrament o-primer-caso-autoctono-covid-19-n626618.

[53] Lemey P, Rambaut A, Welch JJ, et al. Phylogeography takes a relaxed random walk in continuous space and time. Mol Biol Evol. 2010 Aug;27 (8):1877-1885.

[54] Asadu C. SOCIALDISTANCING: How one wedding guest infected 44 Uruguayans. The Cable. 2020. Available from: https://www.thecable.ng/s-o-c-i-a-ld-i-s-t-a-n-c-i-n-g-how-one-wedding-guest-infected44-uruguayans.

[55] El Observador. "Me decían que no era un caso grave", dijo una de las uruguayas con coronavirus. [They told me it was not a serious case," said one of the Uruguayans with coronavirus]. El Observador. 2020. Available from: https://www.elobservador.com.uy/ nota/-me-decian-que-no-era-un-caso-grave-dijo-unade-las-uruguayas-con-coronavirus-2020313194329. Spanish.

[56] Zhang X, Tan Y, Ling Y, et al. Viral and host factors related to the clinical outcome of COVID-19. Nature. 2020 Jul;583(7816):437-440.

[57] Becerra-Flores M, Cardozo T. SARS-CoV-2 viral spike G614 mutation exhibits higher case fatality rate. Int J Clin Pract. 2020 May 6;74(8):e13525.

[58] Toyoshima Y, Nemoto K, Matsumoto S, et al. SARSCoV-2 genomic variations associated with mortality rate of COVID-19. J Hum Genet. 2020 Jul 22;65 (12):1075-1082.

[59] Petrilli CM, Jones SA, Yang J, et al. Factors associated with hospital admission and critical illness among 5279 people with coronavirus disease 2019 in New York city: prospective cohort study. Br Med J. 2020 May 22;369:m1966.

[60] Perez-Guzman PN, Daunt A, Mukherjee S, et al. Clinical characteristics and predictors of outcomes of hospitalized patients with COVID-19 in a multi-ethnic London NHS Trust: a retrospective cohort study. Clin Infect Dis. 2020 Aug 7;ciaa1091. 